Caries Res. 1987;21:559

\title{
Klaus G. König: Editor of Caries Research 1970-1987
}

ORCA, Caries Research and its readership have been extremely privileged to have had the services of Professor Klaus König as Editor for the past 18 years.

Under his guidance the Journal has grown and prospered. It has become the primary international vehicle for the publication of original work in this important dental area.

Professor König's success as Editor was not attributable alone to the unremitting chain of labour to which every Editor is invisibly tied. He contributed a scientific awareness, derived from a thorough practical apprenticeship as an international research worker, and an exceptional literary skill, already well formed at a much earlier period of post-graduate development.

Those of us with the good fortune to have been associated with Klaus König during his long tenure as Editor would like to express our sincere gratitude for this long period of devoted service to our Journal, for his cheerfulness and optimism in often difficult circumstances, for his capacious generosity and for his never failing willingness to help and advise.

The new incumbent of this onerous position as Editor-in-Chief has a formidable example to follow.

John Weatherell President of ORCA 